Article

\title{
The Impact of Pro-environmental Preference on Consumers' Perceived Well-being: The Mediating Role of Self-Determination Need Satisfaction
}

\author{
Jian Gao ${ }^{1,2} \mathbb{D}$, Jianguo Wang ${ }^{1,3, *}$ and Jianming Wang ${ }^{1}$ \\ 1 School of Business Administration, Zhejiang University of Finance and Economics, Hangzhou 310018, China; \\ jettgao@zufe.edu.cn (J.G.); sjwjm@zufe.edu.cn (J.W.) \\ 2 College of Business, Valparaiso University, Valparaiso, IN 46383, USA \\ 3 College of Business and Innovation, The University of Toledo, Toledo, OH 43606, USA \\ * Correspondence: jgwang@zufe.edu.cn; Tel.: +86-159-90174275
}

Received: 5 December 2019; Accepted: 3 January 2020; Published: 6 January 2020

check for updates

\begin{abstract}
This study uses a conceptual research model to explore the mediating role of need satisfaction for competence, relatedness, and autonomy in the relationship between pro-environmental preference (PEP) and consumers' perceived well-being (PWB). The data were collected on WJX (a Chinese online recruitment platform) from a sample of 514 respondents and analyzed using Smart PLS 3. The results indicated that two need satisfactions (competence and autonomy) fully mediate the relationship between PEP and consumers' PWB. However, surprisingly, relatedness need satisfaction has no mediation effect in the relationship between PEP and consumers' PWB. The results demonstrate the pivotal role of self-determination theory in explaining the primary psychological needs that must be met for consumers to perceive heightened states of well-being. Moreover, the results can signify to policymakers how to translate the impact of PEP into consumers' PWB.
\end{abstract}

Keywords: pro-environmental preference; self-determination theory; perceived well-being; mediation effect

\section{Introduction}

With the deterioration of the ecological environment, people gradually realize their responsibility for environmental damage [1] and are more and more willing to engage in pro-environmental behavior (PEB) [2]. As a result, the issue of consumers' PEB has become topical. Evidence of this may be seen in the case of organic products, whose global market size has grown almost from zero to US $\$ 72$ billion during the past 30 years [3]. At the same time, the pursuit of well-being is an everlasting goal for human beings. PEB can both reduce negative emotions and promote positive emotions [4,5]. However, some scholars have argued that consumers can not perceive heightened states of well-being when engaging in PEB, as eco-friendly behaviors are often associated with some extra cost, and even involves some degree of discomfort [1]. In opposition to the negative view of PEB, other scholars have found that PEB can increase consumers' life satisfaction and perceived well-being (PWB) [6-8]. These inconsistent findings provide further research space.

In addition to the foregoing, previous research has found some mediating variables to bridge PEB and consumers' PWB. For example, some scholars have found that engaging in PEB brings about a warm glow that can subsequently increase consumers' life satisfaction and PWB $[7,9,10]$; other scholars found that the relationship between PEB and PWB is mediated by consumers' green self-image [11]. Consistent with self-determination theory (SDT) [12], PEB as an ethical behavior, altruistic behavior, and pro-social behavior naturally has the property of connecting with others. In addition, green products usually have a certain price premium level, so PEB can show consumers' 
economic capability to afford the cost of environmental protection. Yet, when PEB is not a free choice, consumer's autonomy need cannot be satisfied. Compared with warm glow theory and self-image theory, SDT may be a more fundamental reason to uncover the chain effect of PEP on well-being through consumers' self-determination need satisfaction (SDNS). Weinstein and Ryan [13], for example, found that pro-social behaviors (e.g., PEB) can influence consumers' PWB through the path of these basic psychological needs satisfactions.

Whether SDNS is the path from PEP to consumers' PWB or not is still unclear [11]. Thus, the current research applies SDT to explore why engaging in PEB may actually promote consumers' sense of well-being. We propose that preference to engage in PEB in general satisfies consumers' self-determination needs, which in turn improves their well-being. Specifically, PEP will increase well-being perception if consumers' competence need, relatedness need, or autonomy need is satisfied. Besides, prior literature indicates that consumers prefer to perform pro-environmental behaviors when they can gain positive emotions (e.g., well-being) from these behaviors [14]. Therefore, our findings not only can provide theoretical insights into the path from PEP to well-being but can also be of benefit to motivate the maintenance of PEBs over time.

The rest of the paper is arranged as follows. First, there is a discussion of the theoretical background to the study, which includes a discussion of the central constructs under investigation (PEP; SDT, with its focus on needs for competence, relatedness, and autonomy; and consumers' PWB). Following is a development of the hypotheses and the conceptual model linking PEP to consumers' PWB. Next, the methodology section describes how the study was conducted, and this precedes a discussion of the results and implications. Finally, a discussion of research limitations and future research directions are presented.

\section{Theoretical Background}

\subsection{Pro-Environmental Preference (PEP)}

PEB is a broad category that includes purchasing green products, consuming conservatively, and advocating eco-friendly behaviors. Drawing on Carlson, Grove, and Kangun [15], Wu and Yang [1], explain that PEB refers to "the extent to which consumers consider the impact of their own behavior on the environment when they purchase, use, or dispose of products, and try to minimize the negative impact and maximize the positive impact on the environment". On most occasions, preference/intention and behavior are consistent, and research findings have supported this [16,17]. In this study, we focus on PEP, which does not involve actual purchase behavior but the likelihood of selecting one product over another, where the preferred product is one that would enable the consumer to minimize negative impacts on the environment. Hence, the PEP is a proxy variable of PEB. However, the inconsistency between consumers' PEP and their actual behavior is beyond the scope of this study. In the case of the benefits of PEP or PEB to consumers, some scholars have focused on PEB as a tradeoff between cost and benefit to the environment, but not always to the consumer [18]. Yet, a neglected benefit of PEB or PEP is that consumers may use green products and brands to construct and express themselves to some extent. Despite these findings, research has devoted limited attention to further investigations on the psychological process in the relationship between PEB and consumers' PWB. This paper argues that PEP, like PEB, can contribute to feelings of consumer well-being. This claim in anchored in self-determination theory.

\subsection{Self-Determination Theory (SDT)}

SDT suggests that basic psychological needs for competence, relatedness, and autonomy are inborn and critical for continuous psychological growth, internalized motivation, and well-being [12]. SDT suggests well-being happens when people's needs for competence, relatedness, and autonomy are satisfied. The theory assumes that motivation is a multifaceted predicator of behavior that can be based on different levels of self-determination. When consumers are motivated by self-determination, rather 
than being required to act, they are more apt to demonstrate PEBs [19]. Internally motivated people engaging in pro-social behavior regardless of the place or occasion will be more consistent as a result. In contrast, externally motivated people might exhibit pro-social behavior in public places because of social desirability. However, in private, their behavior may change. SDT may help us to understand these behaviors, as it is a widely accepted theory for human motivation that has been applied to a variety of aspects of human behavior [20], including pro-social behaviors [19] and PEBs [21,22].

Among the constructs of relevance to SDT are needs for competence, relatedness, and autonomy [23]. Drawing on Ryan and Deci [24], Olčar et al. [25] indicated that competence need satisfaction (CNS) represents an individual's inborn need to feel competent and effective in interacting with the environment. Furthermore, relatedness need satisfaction (RNS) means caring for others, being cared for, and feeling emotionally connected to other people. Lastly, autonomy need satisfaction (ANS) refers to the experience of choice, ownership of behavior, and psychological freedom. CNS, RNS, and ANS have been shown to be positively related to consumers' well-being. These constructs are further described in the hypotheses section.

\subsection{Perceived Well-Being (PWB)}

Happiness is a pursuing goal for many people [26]. A large number of studies view both concepts of "happiness" and "well-being" as interchangeable without clear distinction. Strictly speaking, wellbeing is only related to the affective dimension, while happiness is related to both dimensions of affect and the evaluation [27]. According to Mihaly Csikszentmihalyi's paradigm [28], a most important goal of positive psychology is to explore what behaviors lead to well-being. Since the main focus of this paper is on how PEB impacts consumers' subsequent emotional responses, consumers' PWB is an ideal outcome for investigation.

Recently, research on the impact of different consumption patterns on well-being has gradually increased. Whether consumption can promote consumers' well-being depends on what they buy and how they consume [29]. Dunn, Aknin, and Norton [30], for example, found that people can get a better sense of well-being in pro-social expenditure than personal expenses. Similarly, Xiao and Li [8] found that PEB is positively related to consumers' PWB. In this study, PWB is a happy feeling through consumers' choosing to buy an eco-friendly air-conditioner or a conventional one. Additionally, we expect that consumers can get a better sense of well-being through buying a pro-environmental product than buying a counterpart. Hence, the well-being here is different from general well-being. Consistent with prior research, SDT has been applied to encourage PEB [31,32]. Yet, few studies examine how environmental actions promote SDNS, and in turn increase subsequent positive emotions. Hence, the current research aims to investigate whether PEP satisfies consumers' needs for competence, relatedness, or autonomy, which further promotes consumers' PWB.

\section{Hypotheses}

\subsection{Pro-Environmental Preference and Consumers' Perceived Well-Being}

A number of scholars have found that PEB can improve consumers' PWB and life satisfaction [7,10]. As previously discussed, PEB is different from conventional consumption behavior. Consumers may engage in PEB for different motivations like costly signaling, social desirability, or purely environmental concern $[33,34]$, which may satisfy their competence need, relatedness need, or autonomy need accordingly. Further, once these self-determination motivations are satisfied, people will experience well-being [35]. Donnelly et al. [36], for example, found that people who engaged in social recycling behavior perceived a better sense of well-being. In that study, social recycling was defined as "disposing of used goods by allowing other consumers to acquire them at no cost". Different from conventional consumption behavior, PEP may be more likely to increase consumers' perceived positive affect, like well-being [14]. Hence, we propose: 
Hypothesis 1 (H1). Consumers with a pro-environmental preference will have a better sense of well-being than consumers without a pro-environmental preference.

\subsection{Pro-Environmental Preference, Competence Need, and Consumers' Perceived Well-Being}

Competence need is synonymous with Bandura's self-efficacy concept. It refers to consumers' belief that their learning behavior or actions can reach a certain level and belief that they are qualified for the activity [12]. Steele [37] suggested that self-affirmation refers to the act of determining the global self-integrity by affirming consumer abilities. Consistent with prior research, income and wealth are positively related to consumers' PWB [38]. Green products usually have a higher price than conventional products. Therefore, engaging in PEB like green consumption requires consumers to have premium payment ability, which further objectively manifests their purchasing power. Griskevicius et al. [33] and Zahavi [39], for example, suggested that costly signaling or status competition can be used to promote PEB. At the same time, consumer's competence perception also stems from the perceived influence of their behavior on the overall environmental protection cause. De Yong [40], for example, found that volunteering to participate in community environmental service activities can enhance consumers' perceived capacity of environmental contribution. Drawing on the logic of previous studies, the above CNS is conducive to enhancing consumers' PWB [25]. Consumers engaging in PEB may satisfy their need for competence, and then get a sense of well-being [41]. Hence, we propose:

Hypothesis 2 (H2). The relationship between pro-environmental preference and consumers' perceived well-being is mediated by consumers' competence need satisfaction.

\subsection{Pro-Environmental Preference, Relatedness Need, and Consumers' Perceived Well-Being}

Relatedness need means that consumers need care, understanding and support from the surrounding physical and social environment, by which they can experience a sense of belonging [12]. Ecologically friendly products, as types of pro-social consumer goods, can satisfy the needs of consumer pro-social motivation. Similarly, impression management motivation will also lead consumers to prefer more pro-environmental products. Chinese society tends to be a more collectivist culture, which leads to their unusual need for relatedness [42]. "Mianzi" consumption is one of the best illustrations. As a crucial cultural element, mianzi, representing the reputation and identity of consumer status, somehow determines the way people behave [43]. When engaging in PEB, consumers can demonstrate their environmental awareness, shape their green self-identity, and even get social desirability [42]. Especially for consumers engaging in these behaviors for themselves while benefiting others, as a byproduct, they may be more willing to interact, communicate, and share such behaviors with others. These showing-off behaviors are conducive to shaping consumers' altruistic image, winning social desirability, and establishing good interpersonal relationships. Thus, showing self-dedication to PEB may satisfy consumers' relatedness need, and in turn increase consumers' PWB [32,35,44]. Hence, we propose:

Hypothesis 3 (H3). The relationship between pro-environmental preference and consumers' perceived well-being is mediated by consumers' relatedness need satisfaction.

\subsection{Pro-Environmental Preference, Autonomy Need, and Consumers' Perceived Well-Being}

Autonomy need means that consumer behavior is driven by their willpower. It is completely consistent with the consumer's core self, and reflects their wholehearted, prioritized and accepted values, which are similar to traditional internal motivation [12]. With the development of a social economy, the accumulation of material wealth and the improvement of consumers' purchasing power, consumption may be an important way for consumers to construct and express their identity. Consumers may expect to discover the "true self" or verify environmental self-identity through pro-environmental actions. Venhoeven et al. [11], for example, pointed out that green products 
themselves have moral attributes, so consumers engaging in such behaviors are often considered to be environmentalists. Compared with consumers engaging in PEBs for situational factors, both egoists and altruists engaging in these behaviors are more likely to be more internally motivated [45]. Obviously, autonomy need is easier to be satisfied for the egoists and altruists [46]. Prior research has shown that voluntary PEB is more likely to stimulate consumer positive self-image perception than situationally-driven PEB [11]. According to centrality theory, PEB is more representative of self-defining than non-pro-environmental behavior. Therefore, people may regard their PEB as something closer to their self-concept.

PEB is more related to positive self-identity and more conducive to self-growth and development [47]. This close relationship with self has in turn produced a potential sense of well-being. Brown and Kasser [7], for example, found that PEB can meet the consumer's need to express values, so it can lead to more intense well-being. Compared with social identity, self-identity is due to the consumer's autonomy need, which can be easier to stimulate than consumer's flow experience [28]. Following this logic, Binder and Blankenberg [48] found that consumers' internal recognition of green self-image inspired their perceived well-being. Especially for purely altruistic environmentalists, they engage in PEB without any external rewards. When consumers perceive their PEB, they will connect the behavior with the emotion of positive, happy and active from the heart. So they can experience the joy of engaging in such pro-environmental actions. This ultimate state of "integration of knowing and doing" is the ultimate experience of well-being or flow experience [49]. Consumers engaging in PEP may possibly experience the satisfaction of need for autonomy, and in turn get a sense of well-being. Hence, we propose:

Hypothesis 4 (H4). The relationship between pro-environmental preference and consumers' perceived well-being is mediated by consumers' autonomy need satisfaction.

Based on the above discussion, Figure 1 shows the proposed conceptual model of this study, which portrays how SDNS mediates the relationship between PEP and consumers' PWB.

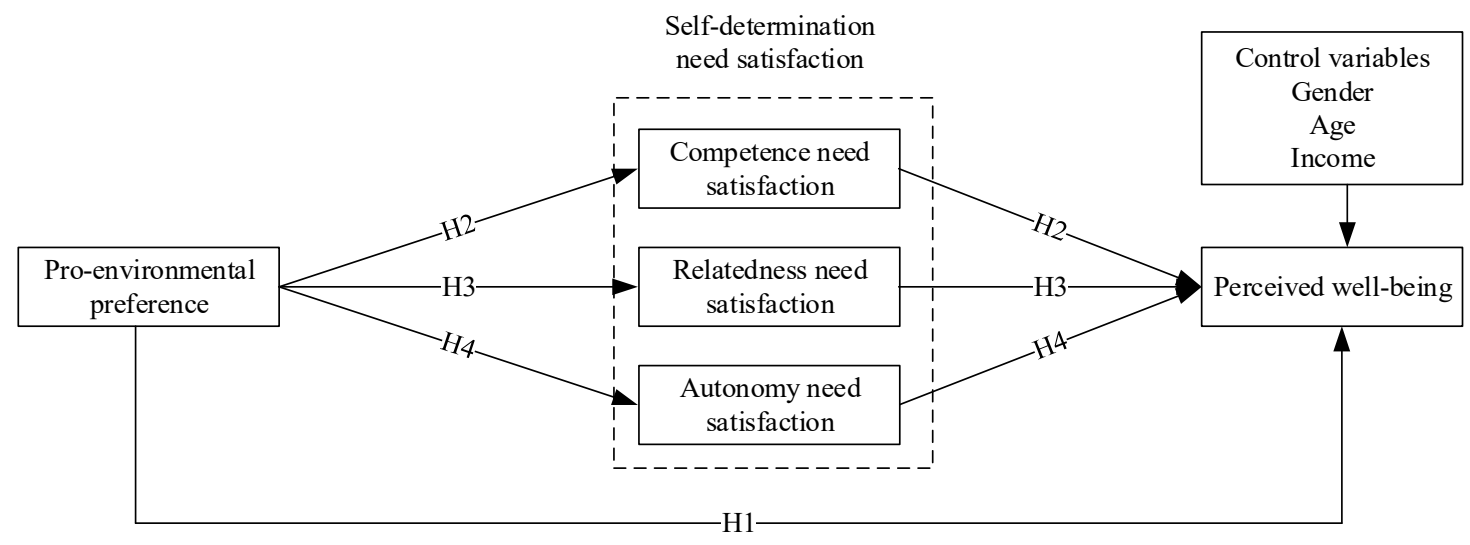

Figure 1. Conceptual model.

\section{Methodology}

\subsection{Data Collection}

Respondents for this research were recruited from WJX, which is the most prominent Chinese online data collection platform. Because PEP can be a sensitive topic, all the participants answered the questionnaire anonymously. The data collection yielded a total of 514 valid questionnaires. Although 39 respondents indicated that Type A is more eco-friendly and 120 respondents indicated that Type A is more expensive, keeping them in or out of the analysis did not significantly influence the result. In these 514 valid questionnaires, some $38 \%$ of the respondents were male, and $62 \%$ were female. On 
average, the participants were 26.73 years old $(\mathrm{SD}=9.52)$, with ages ranging from 18 years to 66 years. With regard to average monthly income (RMB, the Chinese currency, Yuan), 23.06\% earned below $¥ 1000$ (about \$141), 27.33\% earned between $¥ 1000$ and $¥ 3000$ (about \$424), $11.63 \%$ earned between $¥ 3000$ and $¥ 5000$ (about \$707), 23.45\% earned between $¥ 5000$ and $¥ 10,000$ (about $\$ 1415$ ), 10.47\% earned between $¥ 10,000$ and $¥ 20,000$ (about $\$ 2029$ ), and $4.07 \%$ earned above $¥ 20,000$. Some $57 \%$ of the respondents were undergraduate students, and $43 \%$ were not students.

\subsection{Measures}

In this research, all of the measures were adapted from prior literature to ensure content validity. PEP was operationalized as the purchase/non-purchase of an eco-friendly air conditioner. The measure of PEP was adapted from Chuang et al. [50]. Similar to the case in the study by Chuang et al. [50], the participants read the following scenario: "Your house needs an air-conditioner, and your budget is approximately $¥ 3000$ (about \$425). Therefore, you go to the shopping mall. An agent recommends two types of air-conditioner. There are no substantial differences between the two in terms of friction and power consumption. The only specific difference is that the type B model utilizes a fluorine-free refrigerant and is thus more eco-friendly. However, the price of the type B air-conditioner is greater than that of the type A model by $¥ 600$ (about \$85)." After participants read the scenario, they answered the question, "If you decide to buy an air-conditioner, which one would you prefer to buy?" The response to this question was a measure of pro-environmental preference (Type $A=0$; Type $B=1$ ). As a manipulation check, participants further indicated the relative degree of difference between these two air-conditioners along the following two dimensions: (1) being more eco-friendly ('Which air conditioner is more eco-friendly?'), and (2) being more expensive ('Which air conditioner is more expensive?').

The participants then completed responses to items used to measure SDNS (consisting of CNS, RNS, and ANS) and their perceived well-being. They also responded to demographic questions. SDNS was measured using the nine-item scale from La Guardia [51]. Three items each measured each component of SDNS. Consumers' PWB was measured using the four-item scale from Van Boven and Gilovich [29]. A 5-point measurement scale was used, ranging from "strongly disagree - 1 " to "strongly agree - 5". We first translated the original English questionnaire items into Chinese and then we translated them back into English. Then, we made comparison between the two English versions to see if there was any mismatch, so we could make sure to be consistent with the original measures. Appendix A contains additional information on all the items used for the measures.

\section{Results and Discussion}

\subsection{Manipulation Checks}

We conducted a manipulation check to detect perceived differences in the air conditioners in the scenarios. The results from this manipulation check showed that air-conditioner $B$ was considered to be more eco-friendly than air-conditioner A, as $92 \%$ of the respondents indicated that air-conditioner $\mathrm{B}$ was eco-friendly, and $8 \%$ of the respondents indicated that air-conditioner A was eco-friendly. In addition, air-conditioner $\mathrm{B}$ was perceived to be more expensive than air-conditioner $\mathrm{A}$, since $77 \%$ of the respondents indicated that air-conditioner $\mathrm{A}$ was cheaper, and $23 \%$ of the respondents indicated that air-conditioner B was cheaper. In order to check the baseline of consumers' preference for the targeted products, the respondents were asked about their interest in air conditioners. Consistent with our expectations, some $83 \%$ of the respondents indicated that they did not hold special interest in air conditioners.

\subsection{Measurement Model}

Data analysis was conducted using Smart PLS 3. To assess the quality of the measurement model evaluation, there was an investigation of outer loadings, composite reliability, convergent validity, 
and discriminant validity (Table 1 ; Table 2). The composite reliability for each construct exceeded the threshold value of 0.7 [52] (see Table 1). In addition, all but one of the Cronbach alpha $(\alpha)$ values were greater than the critical value of 0.7 . The measures of convergent validity, average variance extracted (AVEs), all exceeded the 0.5 threshold value [53]. As a result, this shows that all the constructs have convergent validity (Table 1 ).

Table 1. Outer loadings, reliability, and average variance extracted (AVEs).

\begin{tabular}{|c|c|c|c|c|c|}
\hline Construct & Item & Outer Loadings & $\alpha$ & Composite Reliability & AVEs \\
\hline $\begin{array}{l}\text { Pro-environmental } \\
\text { preference (PEP) }\end{array}$ & PEP1 & 1.000 & 1.000 & 1.000 & 1.000 \\
\hline \multirow{3}{*}{$\begin{array}{l}\text { Competence need } \\
\text { satisfaction (CNS) }\end{array}$} & CNS-1 & 0.825 & \multirow{3}{*}{0.652} & \multirow{3}{*}{0.812} & \multirow{3}{*}{0.591} \\
\hline & CNS-2 & 0.728 & & & \\
\hline & CNS-3 & 0.750 & & & \\
\hline \multirow{3}{*}{$\begin{array}{l}\text { Relatedness need } \\
\text { satisfaction (RNS) }\end{array}$} & RNS-1 & 0.777 & \multirow{3}{*}{0.712} & \multirow{3}{*}{0.838} & \multirow{3}{*}{0.633} \\
\hline & RNS-2 & 0.787 & & & \\
\hline & RNS-3 & 0.822 & & & \\
\hline \multirow{3}{*}{$\begin{array}{l}\text { Autonomy need } \\
\text { satisfaction (ANS) }\end{array}$} & ANS-1 & 0.835 & \multirow{3}{*}{0.761} & \multirow{3}{*}{0.862} & \multirow{3}{*}{0.677} \\
\hline & ANS-2 & 0.875 & & & \\
\hline & ANS-3 & 0.754 & & & \\
\hline \multirow{4}{*}{$\begin{array}{l}\text { Perceived well-being } \\
\text { (PWB) }\end{array}$} & PWB-1 & 0.868 & \multirow{4}{*}{0.895} & \multirow{4}{*}{0.927} & \multirow{4}{*}{0.761} \\
\hline & PWB-2 & 0.877 & & & \\
\hline & PWB-3 & 0.884 & & & \\
\hline & PWB-4 & 0.860 & & & \\
\hline
\end{tabular}

Table 2. Discriminant validity.

\begin{tabular}{cccccc}
\hline Construct & $\mathbf{1}$ & $\mathbf{2}$ & $\mathbf{3}$ & $\mathbf{4}$ & $\mathbf{5}$ \\
\hline $\begin{array}{c}\text { Pro-environmental } \\
\text { preference }\end{array}$ & $\mathbf{1 . 0 0 0}$ & & & & \\
$\begin{array}{c}\text { Competence need } \\
\text { satisfaction }\end{array}$ & 0.255 & $\mathbf{0 . 7 6 9}$ & & & \\
$\begin{array}{c}\text { Relatedness need } \\
\text { satisfaction }\end{array}$ & 0.190 & 0.746 & $\mathbf{0 . 7 9 6}$ & & \\
$\begin{array}{c}\text { Autonomy need } \\
\text { satisfaction }\end{array}$ & 0.257 & 0.756 & 0.688 & $\mathbf{0 . 8 2 3}$ & \\
$\quad \begin{array}{c}\text { Perceived well-being } \\
\text { Notes: The off-diagonal numbers are the correlations. AVE square roots are bolded on the diagonal. }\end{array}$ & 0.241 & 0.606 & 0.491 & 0.641 & $\mathbf{0 . 8 7 2}$ \\
\hline
\end{tabular}

Table 2 contains information on the assessment of the discriminant validity of the measurement model. The results show that the maximum correlation of any pair of constructs was 0.756 , while the minimum square root of the AVE was 0.769. Therefore, the square root of the AVE for each construct was greater than those for all the inter-construct correlations. These results show that the model possesses discriminant validity [53].

In order to further discuss the measurement model, we examined common method bias (CMB) tand inner variance inflation factor (VIF) values. The results of Harmon's single-factor test showed that the first construct is equal to $40.86 \%$, and does not exceed $50 \%$ of the total variance. Thus, $\mathrm{CMB}$ is not a major concern in this study. According to inner variance inflation factor (VIF) values (Table 3), the largest value is 3.1 , which is less than the threshold value of 5.0. Thus, there is no multicollinearity among the variables of PEP, CNS, RNS, and ANS. 
Table 3. Inner variance inflation factor (VIF) values.

\begin{tabular}{ll}
\hline & PWB \\
\hline PEP & 1.094 \\
CNS & 3.100 \\
RNS & 2.461 \\
ANS & 2.672 \\
\hline
\end{tabular}

\subsection{Assessment of Structural Model}

To assess the mediating role of a construct, we followed these steps [54-57]. First, we assessed the total effect and the corresponding significant value of impact of the independent variable on the dependent variable (Table 4). A positive and significant result would lead to the assessment of the indirect effect (the impact of independent variable on dependent variable through the mediating variable) (Table 5). A significant and positive result indicates the possibility of full or partial mediation. A non-significant finding would suggest no mediation. Finally, to assess whether there was full or partial mediation, we assessed the direct effect of the independent variable on the dependent construct (Table 6; Figure 2). A significant result, along with a value of the path coefficient decreasing, as compared to the total effects, would indicate a case of partial mediation. If this was not the case, then there was full mediation. These steps formed the basis for the testing of the four hypotheses.

Table 4. Total effects.

\begin{tabular}{ccccc}
\hline & Path Coefficients & Standard Deviation & T Statistics & $p$ Values \\
\hline $\mathbf{P E P} \rightarrow$ PWB & 0.240 & 0.044 & 5.427 & 0.000 \\
$\mathbf{P E P} \rightarrow$ CNS & 0.255 & 0.042 & 6.073 & 0.000 \\
$\mathbf{C N S} \rightarrow$ PWB & 0.293 & 0.078 & 3.749 & 0.000 \\
$\mathbf{P E P} \rightarrow$ RNS & 0.190 & 0.044 & 4.322 & 0.000 \\
$\mathbf{R N S} \rightarrow$ PWB & -0.031 & 0.059 & 0.528 & 0.597 \\
$\mathbf{P E P} \rightarrow$ ANS & 0.257 & 0.043 & 5.995 & 0.000 \\
ANS $\rightarrow$ PWB & 0.422 & 0.066 & 6.372 & 0.000 \\
\hline
\end{tabular}

Table 5. Indirect effects.

\begin{tabular}{|c|c|c|c|c|}
\hline \multicolumn{2}{|c|}{ Path Coefficients } & \multirow{2}{*}{$\begin{array}{l}\text { Standard Deviation } \\
\text { tal indirect effect }\end{array}$} & \multirow{2}{*}{ T Statistics } & \multirow{3}{*}{$\begin{array}{c}p \text { Values } \\
0.000\end{array}$} \\
\hline & & & & \\
\hline $\mathrm{PEP} \rightarrow \mathrm{PWB}$ & 0.177 & 0.029 & 6.162 & \\
\hline \multicolumn{5}{|c|}{ Specific indirect effects } \\
\hline $\mathrm{PEP} \rightarrow \mathrm{CNS} \rightarrow \mathrm{PWB}$ & 0.075 & 0.023 & 3.239 & 0.001 \\
\hline $\mathrm{PEP} \rightarrow \mathrm{RNS} \rightarrow \mathrm{PWB}$ & -0.006 & 0.012 & 0.508 & 0.612 \\
\hline $\mathrm{PEP} \rightarrow \mathrm{ANS} \rightarrow \mathrm{PWB}$ & 0.109 & 0.024 & 4.458 & 0.000 \\
\hline
\end{tabular}

Table 6. Direct effects.

\begin{tabular}{ccccc}
\hline & Path Coefficients & Standard Deviation & T Statistics & $p$ Values \\
\hline $\mathbf{P E P} \rightarrow$ PWB & 0.063 & 0.037 & 1.693 & 0.091 \\
$\mathbf{P E P} \rightarrow$ CNS & 0.255 & 0.042 & 6.073 & 0.000 \\
$\mathbf{C N S} \rightarrow$ PWB & 0.293 & 0.078 & 3.749 & 0.000 \\
$\mathbf{P E P} \rightarrow$ RNS & 0.190 & 0.044 & 4.322 & 0.000 \\
$\mathbf{R N S} \rightarrow$ PWB & -0.031 & 0.059 & 0.528 & 0.597 \\
$\mathbf{P E P} \rightarrow$ ANS & 0.257 & 0.043 & 5.995 & 0.000 \\
$\mathbf{A N S} \rightarrow$ PWB & 0.422 & 0.066 & 6.372 & 0.000 \\
\hline
\end{tabular}




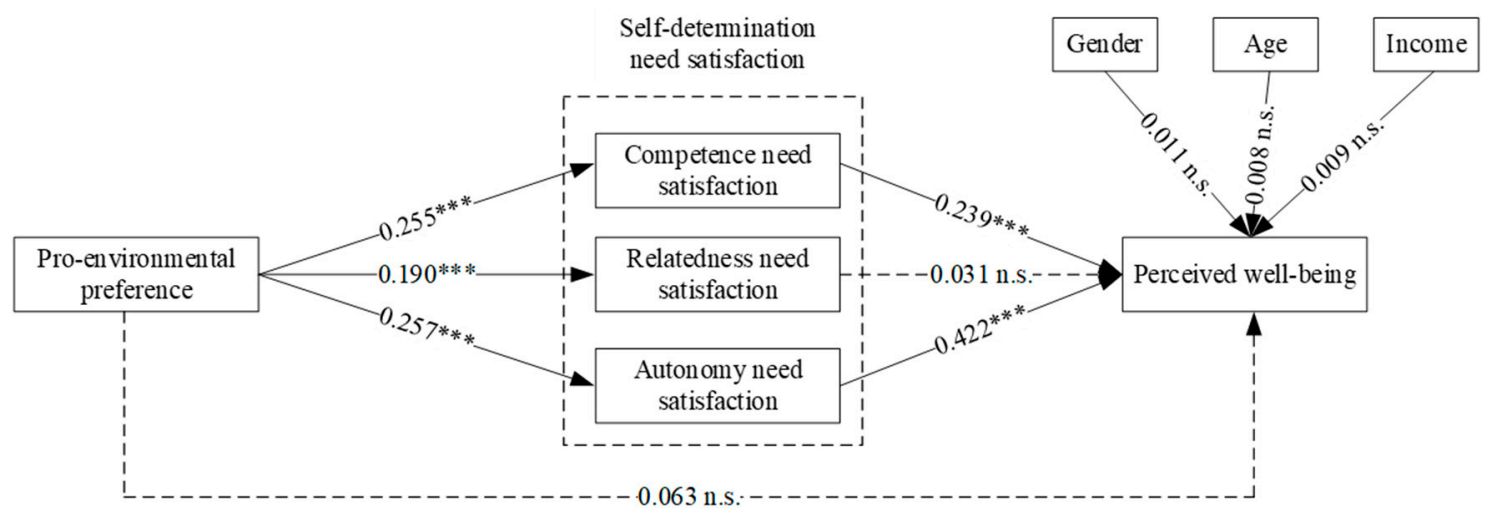

Notes: ${ }^{*}$ means $p<0.05 ;{ }^{* *}$ means $p<0.01 ;{ }^{* *}$ means $p<0.001 ;$ n.s. means $p>0.05$.

Figure 2. Path coefficients.

H1 predicted that consumers with a PEP would have a better sense of well-being than those without a PEP. However, this was not supported as the path coefficient for the direct effect of PEP on consumers' PWB was positive but insignificant ( $\beta=0.063, p>0.05$; Table 6; Figure 2).

In the case of $\mathrm{H} 2$, the prediction was that consumers' CNS would mediate the relationship between PEP and perceived well-being. The results showed that consumers' CNS fully mediates this relationship, as the path coefficient for the direct effect of PEP on consumers' PWB after the inclusion of the mediating variable was positive but insignificant $(\beta=0.063, p>0.05$; Table 6 ; Figure 2), but the indirect effect of PEP on perceived well-being through consumers' CNS was positive and significant $(\beta=0.075, p<0.01$; Table 5).

H3 predicted that consumers' RNS would mediate the relationship between PEP and perceived well-being. However, this hypothesis was not supported. Though the total effect of PEP on consumers' PWB was positive and significant ( $\beta=0.240, p<0.001$; Table 4$)$, the indirect effect of PEP on perceived well-being through consumers' RNS was negative and insignificant $(\beta=-0.006, p>0.05$; Table 5).

Finally, $\mathrm{H} 4$ predicted that consumers' ANS would mediate the relationship between PEP and consumers' PWB. The results supported $\mathrm{H} 4$, as there was full mediation. The direct effect of PEP on consumers' PWB after the inclusion of the mediating variable was positive but insignificant $(\beta=0.063$, $p>0.05$; Table 6; Figure 2). However, the indirect effect of PEP on perceived well-being through consumers' ANS was positive and significant $(\beta=0.109, p<0.001$; Table 5$)$.

\section{General Discussion}

The aim of this study was to test a model of the mediating role of self-determination need satisfaction (SDNS) on the relationship between consumers' pro-environmental preference (PEP) and perceived well-being (PWB) for the very first time. Data were collected from a sample of 514 respondents on WJX. The results indicated that two needs satisfaction, competence need satisfaction (CNS) and autonomy need satisfaction (ANS), fully mediate the relationship between PEP and consumers' PWB. However, conflictingly, relatedness need satisfaction (RNS) had no mediation effect on the relationship between PEP and consumers' PWB because RNS did not significantly impact consumers' PWB.

\subsection{Theoretical Contributions}

Our findings further the research on positive pro-environmental behavior (PEB) spillover effect in two important ways. First, our research provides plausible explanations for the inconsistent findings in the literature on PEB and PWB. Second, our research identifies a neglected and pivotal path (SDNS) from PEP to consumers' PWB.

The results on the mediating role of two SDNS (CNS and ANS) on the relationship between PEP and consumers' PWB verify self-determination theory (SDT) [12], costly signaling theory [39], and 
social recycling theory [36]. The results from the testing of $\mathrm{H} 2$, which predicted that consumers' $\mathrm{CNS}$ mediates the relationship between PEP and PWB, align with the findings of prior studies on PEB [33], self-determination theory [40], and well-being [25]. Consistent with results from prior research, PEBs such as green consumption might be divided into different stages like purchasing green products, consuming conservatively, and recycling behavior. When consumers initially pay the premium for green products, their competence need will be satisfied first. Then, in the stage of consuming and recycling, consumers' relatedness need and autonomy need might in turn be satisfied.

In the case of the testing of $\mathrm{H} 3$, the results do not align with the findings of prior studies on RNS and consumers' PWB. The insignificance of the result might be attributed to the psychological disorder or self-depletion resulting from the pseudo-environmentalist's conspicuous PEB. Although self-proclaimed environmentalists can act based on social desirability, and even fulfill relatedness need by showing their PEP, they might not in turn get an obvious sense of well-being. Since consumers are not innately motivated to engage in PEB [33], those extrinsically motivated actions may lead to consumers' psychological disorder or self-depletion, which in turn lead to a reduction of their perceived well-being. Nonetheless, we advance previous research further by clarifying that RNS cannot explain the relationship between PEP and consumers' PWB [11].

Non-support of H3 regarding the mediating role of RNS also defies Ryan and Deci's SDT, and competitive altruism theory [58]. In this case, the lack of support might be attributed to consumers who are extrinsically motivated to act eco-friendly, but may violate their innate psychological need for relatedness. Especially for the pseudo-environmentalists, there may be a discrepancy in the relationship between their green value and actual PEB. In such a situation, engaging in PEB may lead to consumers' psychological disorder or self-depletion. As a result, they cannot in turn get any sense of well-being.

These results from the testing of $\mathrm{H} 4$ align with the findings of prior studies on PEB and consumers' PWB [11]. Making the choice to engage in certain behaviors rather than acting out of situational constraints may reveal something in particular about who consumers are, not only to others but also to themselves [59]. PEB is linked with a more general positive self-image. Consumers will get a higher feeling of well-being when they engage in behaviors voluntarily rather than when they engage in behaviors due to situational constraints. As a case in point, real environmentalists with a more salient sense of autonomy often integrate environmental concerns into their social value orientation $[2,60]$ and might be more likely to avoid distressful cognitive dissonance [41]. Therefore, their engaging in PEB may significantly increase their perceived well-being.

\subsection{Managerial Implications}

Policymakers are usually mindful of the importance of consumer well-being on society, in general, and on individuals in particular. In light of the results that show the positive effects of pro-environmental behaviors on consumer well-being, policymakers could encourage communication that focuses on highlighting the positive benefits from pro-environmental behavior. To be specific, policymakers can boost consumers' PWB from PEP by satisfying their competence need and autonomy need rather than satisfying their relatedness need. The reason is that this study's results indicate a chain effect of PEP on perceived well-being through consumers' CNS and ANS, not through their RNS. In addition to developing their own marketing communication messages, they could also encourage marketing communicators to develop similar messages in marketing their brands. Policymakers could also adopt laws and strategies that facilitate and promote pro-environmental preferences and behaviors. Furthermore, prior literature has shown that consumers are more likely to engage in pro-environmental actions when they gain positive emotions (e.g., well-being) from the behaviors [61,62]. Therefore, the findings of the research can not only provide policymakers with paths from PEP to consumers' PWB, but also can maintain consumers' PEB over time. 


\subsection{Limitations and Future Research Directions}

Despite the contributions of this study, there are limitations, some of which can be the basis for future research. First, our research used product choice as a measure of PEP. Although previous scholars have found consumers' PWB is more about self-image than actual behaviors [48], we do not know whether our findings can extend to actual PEB or not. Future studies can focus on actual PEB rather than just likely product choice, though this is a close proxy. Second, our study looked at one particular product class: air conditioners, which is a high-involvement product; therefore, more effortful deliberation may go into the choice of this product than the choice for a low-involvement product. Future studies should explore purchases of low-involvement products to determine whether there are differences in pro-environmental consumer behaviors based on the level of product involvement. The study results show, nonetheless, that consumer decisions about high-involvement products can be affected by pro-environmental preferences. In addition, the model does not take into account a number of different variables that can influence pro-environmental consumer behaviors. Third, the $\alpha$ value of CNS is relatively low. Future research should develop new measures to improve the quality of the results. Finally, there is a scant amount of empirical studies on the underlying mechanism like the boundary conditions of PEP on consumers' PWB. Further research on those gaps can be carried out.

Author Contributions: Formal analysis, methodology, J.G.; Writing-original draft, writing-review and editing, J.W. (Jianguo Wang); Funding acquisition, supervision, J.W. (Jianming Wang). All authors have read and agreed to the published version of the manuscript.

Funding: This research was funded by key projects of the national social science of China [No. 18AZD015].

Conflicts of Interest: The authors declare no conflict of interest.

\section{Appendix A}

\begin{tabular}{|c|}
\hline Items used in measures of variables in model \\
\hline Pro-environmental preference (Type $\mathrm{A}=0$; Type $\mathrm{B}=1$ ) \\
\hline After reading the scenario, which air-conditioner will I choose? \\
\hline Competence need satisfaction $(1=$ strongly disagree; $5=$ strongly agree; $\alpha=0.652)$ \\
\hline When engaging in pro-environmental behavior, I feel like a competent person. \\
\hline When engaging in pro-environmental behavior, I often feel inadequate or incompetent. (R) \\
\hline When engaging in pro-environmental behavior, I feel very capable and effective. \\
\hline Relatedness need satisfaction $(1=$ strongly disagree; $5=$ strongly agree; $\alpha=0.712)$ \\
\hline When engaging in pro-environmental behavior, I feel loved and cared about. \\
\hline When engaging in pro-environmental behavior, I feel a lot of distance in my relationship with others. (R) \\
\hline When engaging in pro-environmental behavior, I feel a lot of closeness and intimacy. \\
\hline Autonomy need satisfaction $(1=$ strongly disagree; $5=$ strongly agree; $\alpha=0.761)$ \\
\hline When engaging in pro-environmental behavior, I feel free to be who I am. \\
\hline $\begin{array}{l}\text { When engaging in pro-environmental behavior, I have a say in what happens and can voice my opinion. } \\
\text { When engaging in pro-environmental behavior, I feel controlled and pressured to be certain ways. (R) }\end{array}$ \\
\hline Perceived well-being $(1=$ strongly disagree; $5=$ strongly agree; $\alpha=0.895)$ \\
\hline When you think about this purchase, how happy does it make you? \\
\hline How much does this purchase contribute to your happiness in life? \\
\hline To what extent would you say this purchase is money well-spent? \\
\hline $\begin{array}{l}\text { To what extent do you think the money spent on this purchase would have been better spent on something } \\
\text { else-some other type of purchase that would have made you happier? }\end{array}$ \\
\hline
\end{tabular}

\section{References}

1. Wu, B.; Yang, Z. The impact of moral identity on consumers' green consumption tendency: The role of perceived responsibility for environmental damage. J. Environ. Psychol. 2018, 59, 74-84. [CrossRef]

2. Perera, C.; Auger, P.; Klein, J. Green Consumption Practices Among Young Environmentalists: A Practice Theory Perspective. J. Bus. Ethics 2018, 152, 843-864. [CrossRef] 
3. Juhl, H.J.; Fenger, M.H.J.; Thøgersen, J. Will the consistent organic food consumer step forward? An empirical analysis. J. Consum. Res. 2017, 44, 519-535. [CrossRef]

4. White, K.; Habib, R.; Hardisty, D.J. How to SHIFT consumer behaviors to be more sustainable: A literature review and guiding framework. J. Mark. 2019, 83, 22-49. [CrossRef]

5. Sun, M.; Trudel, R. The effect of recycling versus trashing on consumption: Theory and experimental evidence. J. Mark. Res. 2017, 54, 293-305. [CrossRef]

6. Kasser, T.; Sheldon, K. What Makes for a Merry Christmas? J. Happiness Stud. 2002, 3, 313-329. [CrossRef]

7. Brown, K.W.; Kasser, T.I.M. Are psychological and ecological well-being compatible? The role of values, mindfulness, and lifestyle. Soc. Indic. Res. 2005, 74, 349-368. [CrossRef]

8. Xiao, J.J.; Li, H. Sustainable Consumption and Life Satisfaction. Soc. Indic. Res. 2011, 104, 323-329. [CrossRef]

9. Welsch, H.; Kühling, J. Are pro-environmental consumption choices utility-maximizing? Evidence from subjective well-being data. Ecol. Econ. 2011, 72, 75-87. [CrossRef]

10. Welsch, H.; Kühling, J. Pro-environmental behavior and rational consumer choice: Evidence from surveys of life satisfaction. J. Econ. Psychol. 2010, 31, 405-420. [CrossRef]

11. Venhoeven, L.A.; Bolderdijk, J.W.; Steg, L. Why acting environmentally-friendly feels good: Exploring the role of self-image. Front. Psychol. 2016, 7, 1990-1991. [CrossRef]

12. Deci, E.L.; Ryan, R.M. Motivation and Self-Determination in Human Behavior; Plenum Press: New York, NY, USA, 1985.

13. Weinstein, N.; Ryan, R.M. When Helping Helps: Autonomous Motivation for Prosocial Behavior and Its Influence on Well-Being for the Helper and Recipient. J. Pers. Soc. Psychol. 2010, 98, 222-244. [CrossRef] [PubMed]

14. Winterich, K.P.; Nenkov, G.Y.; Gonzales, G.E. Knowing What It Makes: How Product Transformation Salience Increases Recycling. J. Mark. 2019, 83, 21-37. [CrossRef]

15. Carlson, L.; Grove, S.J.; Kangun, N. A Content Analysis of Environmental Advertising Claims: A Matrix Method Approach. J. Advert. 1993, 22, 27-39. [CrossRef]

16. Collins, S.E.; Witkiewitz, K.; Larimer, M.E. The theory of planned behavior as a predictor of growth in risky college drinking. J. Stud. Alcohol Drugs 2011, 72, 322-332. [CrossRef] [PubMed]

17. Westaby, J.D. Behavioral reasoning theory: Identifying new linkages underlying intentions and behavior. Organ. Behav. Hum. Decis. Process. 2005, 98, 97-120. [CrossRef]

18. White, K.; Simpson, B. When Do ( and Don't) Normative Consumer Behaviors? J. Mark. 2013, 77, 78-95. [CrossRef]

19. Thøgersen, J. Norms for environmentally responsible behaviour: An extended taxonomy. J. Environ. Psychol. 2007, 26, 247-261. [CrossRef]

20. Ryan, R.M.; Deci, E.L. Self-Determination Theory: Basic Psychological Needs in Motivation, Development, and Wellness; Guilford Press: New York, NY, USA, 2017.

21. Osbaldiston, R.; Sheldon, K.M. Promoting internalized motivation for environmentally responsible behavior: A prospective study of environmental goals. J. Environ. Psychol. 2003, 23, 349-357. [CrossRef]

22. Groot, J.I.M.; De Steg, L. Relationships between value orientations, self-determined motivational types and pro-environmental behavioural intentions. J. Environ. Psychol. 2010, 30, 368-378. [CrossRef]

23. Ryan, R.M. Psychological Needs and the Facilitation of Integrative Processes. J. Pers. 1995, 63, $397-427$. [CrossRef] [PubMed]

24. Ryan, R.M.; Deci, E.L. Self-Determination Theory and the Facilitation of Intrinsic Motivation, Social Development, and Well-Being. Am. Psychol. 2000, 55, 68-78. [CrossRef] [PubMed]

25. Olčar, D.; Rijavec, M.; Ljubin Golub, T. Primary School Teachers' Life Satisfaction: The Role of Life Goals, Basic Psychological Needs and Flow at Work. Curr. Psychol. 2019, 38, 320-329. [CrossRef]

26. Lyubomksky, S.; Sheldon, K.M.; Schkade, D. Pursuing happiness: The architecture of sustainable change. Rev. Gen. Psychol. 2005, 9, 111-131. [CrossRef]

27. Carlquist, E.; Ulleberg, P.; Delle Fave, A.; Nafstad, H.E.; Blakar, R.M. Everyday Understandings of Happiness, Good Life, and Satisfaction: Three Different Facets of Well-being. Appl. Res. Qual. Life 2017, 12, 481-505. [CrossRef]

28. Csikszentmihalyi, M. Positive psychology: An introduction. In Flow and the Foundations of Positive Psychology; Springer: Dordrecht, The Netherlands, 2000; pp. 279-298. 
29. Van Boven, L.; Gilovich, T. To Do or to Have? That Is the Question. J. Pers. Soc. Psychol. 2003, 85, 1193-1202. [CrossRef]

30. Dunn, E.W.; Aknin, L.B.; Norton, M.I. Spending money on others promotes happiness. Science 2008, 319, 1687-1688. [CrossRef]

31. Pelletier, L.G.; Sharp, E. Persuasive Communication and Proenvironmental Behaviours: How Message Tailoring and Message Framing Can Improve the Integration of Behaviours Through Self-Determined Motivation. Can. Psychol. Psychol. Can. 2008, 49, 210-217. [CrossRef]

32. Ryan, R.M.; Huta, V.; Deci, E.L. Living well: A self-determination theory perspective on eudaimonia. J. Happiness Stud. 2008, 9, 139-170. [CrossRef]

33. Griskevicius, V.; Tybur, J.M.; Van den Bergh, B. Going Green to Be Seen: Status, Reputation, and Conspicuous Conservation. J. Pers. Soc. Psychol. 2010, 98, 392-404. [CrossRef]

34. Kronrod, A.; Grinstein, A.; Wathieu, L. Go Green! Should Environmental Messages Be So Assertive? J. Mark. 2012, 76, 95-102. [CrossRef]

35. Ryan, R.M.; Deci, E.L. On happiness and human potentials: A review of research on hedonic and eudaimonic well-being. Annu. Rev. Psychol. 2001, 52, 141-166. [CrossRef] [PubMed]

36. Donnelly, G.E.; Lamberton, C.; Reczek, R.W.; Norton, M.I. Social Recycling Transforms Unwanted Goods into Happiness. J. Assoc. Consum. Res. 2017, 2, 48-63. [CrossRef]

37. Steele, C.M. The psychology of self-affirmation: Sustaining the integrity of the self. In Key Readings in Social Psychology; Baumeister, R.F., Ed.; Psychology Press: New York, NY, USA, 1999.

38. Clark, A.E. Four Decades of the Economics of Happiness: Where Next? Rev. Income Wealth 2018, 64, $245-269$. [CrossRef]

39. Zahavi, A. Mate selection-A selection for a handicap. J. Theor. Biol. 1975, 53, 205-214. [CrossRef]

40. De Young, R. Some psychological aspects of reduced consumption behavior: The role of intrinsic satisfaction and competence motivation. Environ. Behav. 1996, 28, 358-409. [CrossRef]

41. Xu, L.; Ling, M.; Wu, Y. Economic incentive and social influence to overcome household waste separation dilemma: A field intervention study. Waste Manag. 2018, 77, 522-531. [CrossRef]

42. Chen, K.; Ren, C.; Gu, R.; Zhang, P. Exploring purchase intentions of new energy vehicles: From the perspective of frugality and the concept of "mianzi". J. Clean. Prod. 2019, 230, 700-708. [CrossRef]

43. Li, J.J.; Su, C. How face influences consumption A comparative study of American and Chinese consumers. Int. J. Mark. Res. 2007, 49, 237-256.

44. Abdulrazak, S.; Quoquab, F. Exploring Consumers' Motivations for Sustainable Consumption: A Self-Deterministic Approach. J. Int. Consum. Mark. 2018, 30, 14-28. [CrossRef]

45. Garvey, A.M.; Bolton, L.E. Eco-product choice cuts both ways: How proenvironmental licensing versus reinforcement is contingent on environmental consciousness. J. Public Policy Mark. 2017, 36, $284-298$. [CrossRef]

46. Evans, J.S.B.T.; Stanovich, K.E. Dual-Process Theories of Higher Cognition: Advancing the Debate. Perspect. Psychol. Sci. 2013, 8, 223-241. [CrossRef] [PubMed]

47. Truelove, H.B.; Yeung, K.L.; Carrico, A.R.; Gillis, A.J.; Raimi, K.T. From plastic bottle recycling to policy support: An experimental test of pro-environmental spillover. J. Environ. Psychol. 2016, 46, 55-66. [CrossRef]

48. Binder, M.; Blankenberg, A.K. Green lifestyles and subjective well-being: More about self-image than actual behavior? J. Econ. Behav. Organ. 2017, 137, 304-323. [CrossRef]

49. Csikszentmihalyi, M. Beyond Boredom and Anxiety; Jossey-Bass: San Francisco, CA, USA, 1975.

50. Chuang, Y.; Xie, X.; Liu, C. Interdependent orientations increase pro-environmental preferences when facing self-interest conflicts: The mediating role of self-control. J. Environ. Psychol. 2016, 46, 96-105. [CrossRef]

51. La Guardia, J.G.; Ryan, R.M.; Couchman, C.E.; Deci, E.L. Within-person variation in security of attachment: A self-determination theory perspective on attachment, need fulfillment, and well-being. J. Pers. Soc. Psychol. 2000, 79, 367-384. [CrossRef]

52. Bagozzi, R.P.; Yi, Y. On the evaluation of structural equation models. J. Acad. Mark. Sci. 1988, 16, 74-94. [CrossRef]

53. Fornell, C.; Larcker, D.F. Evaluating Structural Equation Models with Unobservable Variables and Measurement Error. J. Mark. Res. 1981, 18, 39-50. [CrossRef] 
54. Hussain, S.; Shujahat, M.; Malik, M.I.; Iqbal, S.; Mir, F.N. Contradictory results on the mediating roles of two dimensions of trust between transformational leadership and employee outcomes. J. Organ. Eff. People Perform. 2018, 5, 39-63. [CrossRef]

55. Wong, K.K.K. Partial Least Squares Structural Equation Modelling (PLS-SEM) Techniques Using SmartPLS. Mark. Bull. 2013, 24, 1-32.

56. Preacher, K.J.; Hayes, A.F. Asymptotic and resampling strategies for assessing and comparing indirect effects in multiple mediator models. Behav. Res. Methods 2008, 40, 879-891. [CrossRef] [PubMed]

57. Shujahat, M.; Sousa, M.J.; Hussain, S.; Nawaz, F.; Wang, M.; Umer, M. Translating the impact of knowledge management processes into knowledge-based innovation: The neglected and mediating role of knowledge-worker productivity. J. Bus. Res. 2019, 94, 442-450. [CrossRef]

58. Hawkes, K. Why Work An Ancient Version of the Problem of Public Goods. Curr. Anthropol. 1993, 34, 341-361. [CrossRef]

59. Bodner, R.; Prelec, D. Self-signaling and diagnostic utility in everyday decision making. In Collected Essays in Psychology and Economics; Brocas, I., Carillo, J., Eds.; Oxford University Press: Oxford, UK, 2003.

60. Brick, C.; Lai, C.K. Explicit (but not implicit) environmentalist identity predicts pro-environmental behavior and policy preferences. J. Environ. Psychol. 2018, 58, 8-17. [CrossRef]

61. Bonnes, M.; Carrus, G.; Fr1, M. Correlates of pro-sustainability orientation: The affinity towards diversity. J. Environ. Psychol. 2009, 29, 34-43.

62. Peter, P.C.; Honea, H. Targeting Social Messages with Emotions of Change: The Call for Optimism. J. Public Policy Mark. 2012, 31, 269-283. [CrossRef]

(C) 2020 by the authors. Licensee MDPI, Basel, Switzerland. This article is an open access article distributed under the terms and conditions of the Creative Commons Attribution (CC BY) license (http://creativecommons.org/licenses/by/4.0/). 